\title{
Experimental Study on Fracture Energy of Foam Concrete at Different Notch Depth
}

\author{
Mohd Naqiuddin Zamri ${ }^{1}$,Norashidah Abd Rahman ${ }^{2, a}$, Zainorizuan Mohd Jaini ${ }^{2}$, Zulaikha \\ Ahmad $^{1}$, and Siti Amirah Azra Khairuddin ${ }^{1}$ \\ ${ }^{1}$ Faculty of Civil and environmental Engineering, Universiti Tun Hussein Onn Malaysia, Johor, \\ Malaysia \\ ${ }^{2}$ Jamilus Research Center, Faculty of Civil and environmental Engineering, Universiti Tun Hussein \\ Onn Malaysia, Johor, Malaysia
}

\begin{abstract}
Foamed concrete is lightweight concrete formulated from a mixture of concrete mortar and established foam. Generally foamed concrete is known for its low engineering properties. Many researchers had conducted studies and more focused on the physical and mechanical properties of foamed concrete without taking into account the behavior on its fracture energy. Therefore, this study was carried out to investigate the effect of notch-to-depth ratio on fracture energy of foam concrete using three point bending testmethod. Beam specimens with V-notch were prepared at a densityof $1400 \mathrm{~kg} / \mathrm{m}^{3}$ and $1600 \mathrm{~kg} / \mathrm{m}^{3}$. Three different notch-to-depth ratios which were adopted at $0.1,0.3$ and 0.5 . Fracture energy was determined using Hillerborg, Bazant and Comitee euro International du Beton (CEB) models. From the experimental results, it was shown that fracture energy decreases asthe notch-to-depth ratio increases.
\end{abstract}

\section{Introduction}

Foamed concrete is also known as cellular lightweight concrete or aerated concrete. It is produced by mixing ordinary Portland cement, sand with or without additives, water, and preformed foam. This type of concrete is a non-homogenous material that displays complex mechanical behavior. Many experimental studies have investigated the strengths of concrete through tensile, compression, and flexural tests. However, research on the fracture energy of foam concrete is still on-goingand limited. Fracture energy is a dominant factor that governs the initiation, growth, and coalescence of micro-cracks, as well as macroscopic crack propagation, fracture and progressive damage of brittle materials. Fracture energy is an important material behavior that should be studied when foamed concrete is utilized as a structural component. Previous research reported that foamed concrete has a fracture energy level of $15 \mathrm{~N} / \mathrm{m}-40 \mathrm{~N} / \mathrm{m}$ at various densities between $400 \mathrm{~kg} / \mathrm{m}^{3}$ and $1600 \mathrm{~kg} / \mathrm{m}^{3}[1-4]$.

Fracture energy is simply the total amount of work required to break a specimen completely per unit ligament area. Fracture energy basically corresponds to the area of the softening phase at a stress-strain curve, as shown in Figure 1. The area under the curve represents the energy dissipated during the complete separation (formation of the stress-free surface) of a unit area of plain concrete. The area under the initial tangent of the softening

\footnotetext{
${ }^{\text {a }}$ Corresponding author : nrashida@uthm.edu.my
} 
curve is a fraction of the total fracture energy, which is significant in the calculation of the failure load of thetest specimens. This definition relies on the assumption that all of the energy required to break the specimen is transformed into surface energy. However, energy dissipation outside of the fracture zone is also often considered in the determination of fracture energy and should not be overlooked.

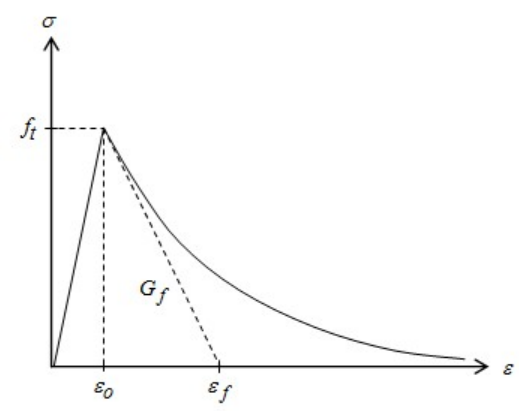

Fig. 1. Fracture energy at the stress-strain curve.

The most commonly method used to determine energy is using the Hillerborg model[5] which is also known as the work of fracture method. Hillerborg model computed the fracture energy as the area under the experimental load-deflection response for notched beam specimen subjected to a three-point bending test. The fracture energy using Hillerborg model can be determined using the Eq. (1):

$$
G_{f}=\frac{U_{o}+m_{g} d_{o}}{B\left(W-a_{o}\right)}
$$

where $U_{o}$ is the area under the softening phase of the stress-strain curve; $B$ is specimen width; $W$ is specimen depth; $a_{o}$ is notch depth; $m_{g}$ is specimen weight; and $d_{o}$ is the load-point deflection at the fracture. Fracture energy can also be predicted based on aggregate size, compressive strength and water-to-cement ratio as suggested by Bazant[6] and Comitee Euro-International du Beton (CEB)[7] models. Eq. (2) and Eq. (3) expressed the formula used to determine fracture energy according to the Bazant and CEB models, respectively:

$$
\begin{aligned}
& G_{F}=2.5 \alpha_{0}\left(\frac{f_{c}}{0.058}\right)^{0.40}\left(1+\frac{D_{\max }}{1.94}\right)^{0.43}\left(\frac{w}{c}\right)^{-0.18} \\
& \left.G_{F}=0.0143 \alpha_{0}\left(D_{\max }\right)^{2}-0.5 D_{\max }+26\right) \times\left(\frac{f_{c}}{10}\right)^{0.7}
\end{aligned}
$$

where $\alpha_{\mathrm{o}}$ is the aggregate shape factor (1.00 for the rounded aggregate and 1.12 for angular aggregate); $D_{\max }$ is the maximum aggregate size; $f_{c}$ is the compressive strength, and $w / c$ is the water-cement ratio of foamed concrete.

\section{Experimental Study}

\subsection{Mix Design and Material Preparation}


The mix design based on the Department of Environment (DOE) was utilized to evaluate the proportions of foamed concrete. The proposed densities of foamed concrete are $1400 \mathrm{~kg} / \mathrm{m}^{3}$ and $1600 \mathrm{~kg} / \mathrm{m}^{3}$. Table 1 shows the mixed design of foam concrete. Ordinary ASTM types 1 Portland cement were used in this study. Fine aggregates have maximum diameters of $3 \mathrm{~mm}$ respectively.

Table 1. Mix design of foam concrete.

\begin{tabular}{llccc}
\hline Type of Concrete & Density $\left(\mathbf{k g} / \mathbf{m}^{\mathbf{3}}\right)$ & \multicolumn{3}{c}{ Ratio } \\
\hline \multirow{3}{*}{ Foamed Concrete } & & $\boldsymbol{C} / \boldsymbol{S}$ & $\boldsymbol{F} / \boldsymbol{C}$ & $\boldsymbol{W} / \boldsymbol{C}$ \\
\cline { 2 - 5 } & 1400 & $2: 1$ & 0.7 & 0.55 \\
& 1600 & $2: 1$ & 0.7 & 0.55 \\
\hline
\end{tabular}

\subsection{Specimen Design}

The Specimen was design based on two standard test methods of RILEM [8] and ASTM E1820-13 [9]. The effective span-to-depth ratio of beam specimen was setup as $S / W=.4$. Hence, the dimension of beam specimen is $700 \mathrm{~mm} \times 150 \mathrm{~mm} \times 150 \mathrm{~mm}$. In the experimental study, a total of $24 \mathrm{~V}$-notched beam specimens with density of $1400 \mathrm{~kg} / \mathrm{m}^{3}$ and $1600 \mathrm{~kg} / \mathrm{m}^{3}$ were prepared for the three-point bending test. V-notched beam specimens were casted with a notch-to-depth ratio of $0.1,0.3$ and 0.5 . V-notch beam specimens were used and positioned at the center of the beam specimen. The specifications of the beam specimen can be referred in Figure 2.

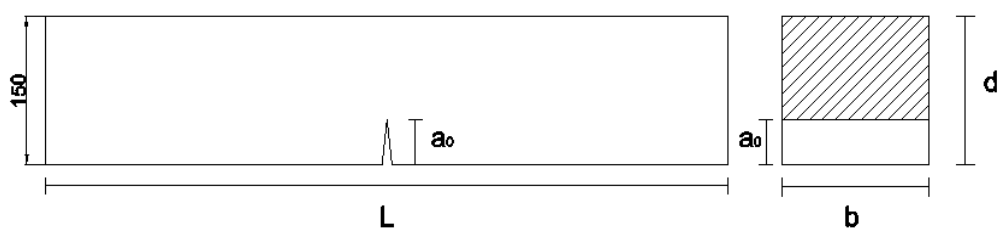

Fig. 2. Schematic design of the V-notched beam specimens, where depth and width of beam, $B$ and $W=150 \mathrm{~mm}$, span of beam, $S=700 \mathrm{~mm}$ and depth of notch, $a_{0}$.

\subsection{Three Point Bending Test}

The three-point bending test was conducted for all beam specimens after 28 days curing period. The universal testing machine was setup to the minimum speed at $0.05 \mathrm{~mm} / \mathrm{min}$ to provide sufficient time during which the propagation of the crack can be detected and to prevent sudden catastrophic failure. The rate of loading should be maintained until failure of the beam specimens. Both supports were hinged with rollers. The beam specimens must be handled carefully during the placement on the testing machine to avoid pre-crack growth. The load, deflection and crack formation of beam specimens were recorded to plot the loaddeflection profile and crack-load history. Figure 3 illustrate the test setup of the beam specimen. In this experimental study, the load and deflection were measured directly from the universal testing machine. The stroke of universal testing machine was calibrated with the linear variable displacement transducer (LVDT) to ensure the validity of data. 


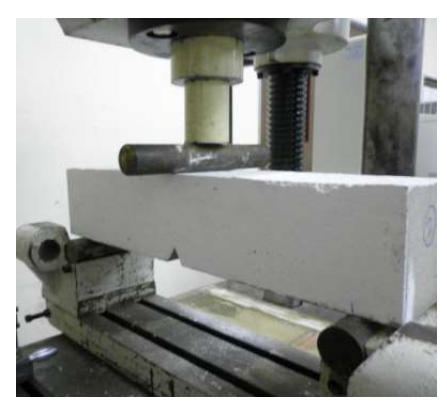

Fig. 3. Three-point bending test for V-notched beam specimen.

\section{Experimental Results}

\subsection{Compressive Strength}

Compressive strength of foam concrete is presented in Figure 4.The strength of foamed concrete at density of $1400 \mathrm{~kg} / \mathrm{m}^{3}$ and $1600 \mathrm{~kg} / \mathrm{m}^{3}$ shows standard compressive strength at 4.6 $\mathrm{MPa}$ and $9.7 \mathrm{MPa}$, respectively.

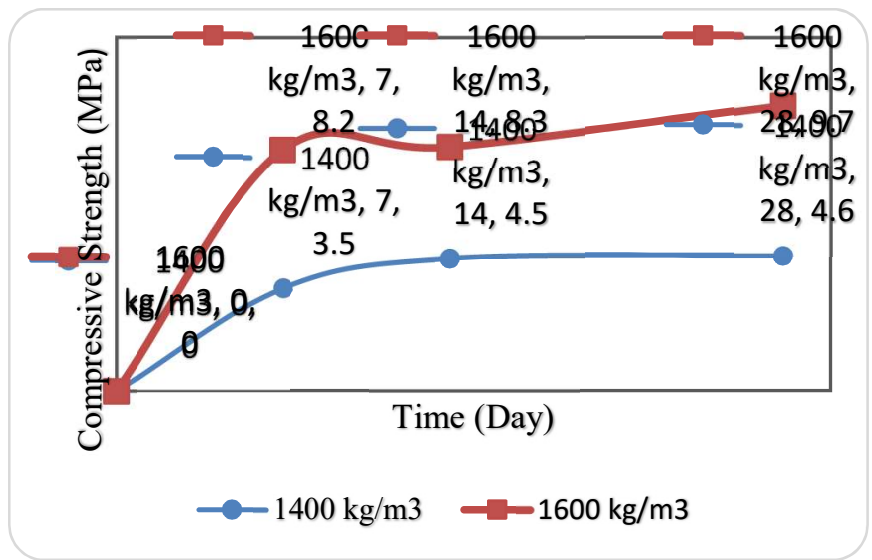

Fig. 4. Cube compressive strength of foam concrete with density of $1400 \mathrm{~kg} / \mathrm{m}^{3}$ (FC1400) and $1600 \mathrm{~kg} / \mathrm{m}^{3}(\mathrm{FC} 1600)$.

\subsection{Load Deflection Profile}

Figure 5 and shows the load deflection profile as obtained during the three-point bending testIt was found that the notch-to-depth ratio at 0.5 significantly had lower value and less ductile compared with the 0.1 and 0.3 . Thus, the area of the load-deflection profile at the notch-to-depth ratio of 0.5 for $1400 \mathrm{~kg} / \mathrm{m}^{3}$ and $1600 \mathrm{~kg} / \mathrm{m}^{3} \mathrm{densities}$ are smaller than 0.1 and 0.3 . This finding significantly affects the fracture energy level. 


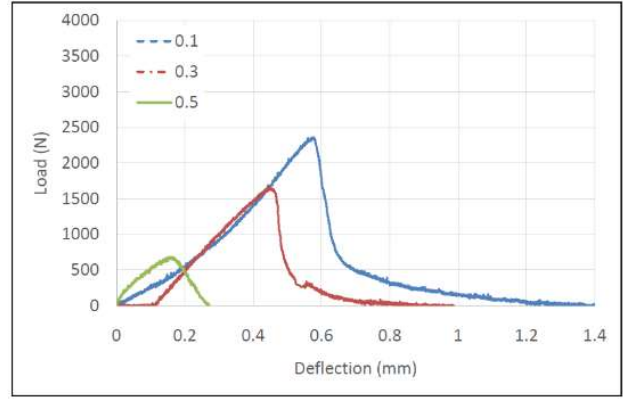

(a)

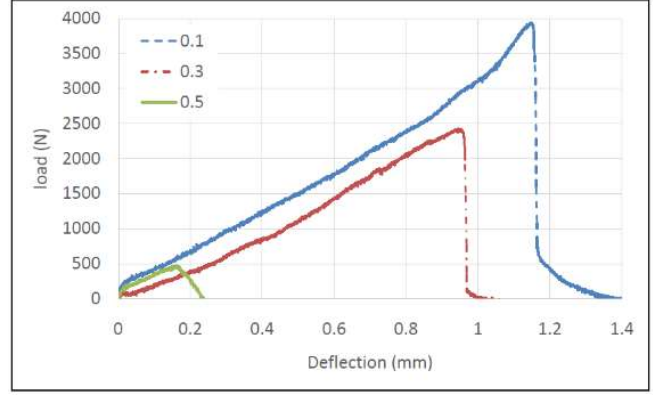

(b)

Figure 5. Load - deflection profile for:(a) density $1400 \mathrm{~kg} / \mathrm{m}^{3}$, and(b) density $1600 \mathrm{~kg} / \mathrm{m}^{3}$.

\subsection{Fracture Energy}

Fracture energy can be calculated using the Hillerborg model and the three-point bending test. Hillerborg methods (Table 2) show that the notch-to-depth ratio affecting the level of fracture energy, where the fracture energydecreasesas thenotch-to-depth ratio increases. Comparedwiththe notch-to-depth ratio of 0.1 and 0.3 , the 0.5 had some abrupt value due to the boundary effect. This is because the created notch at 0.5 ratioswas very close totheboundary of the beam width ofthe Fracture Process Zone. The finding was similar to the experiment done by Naik Partha Uday[10]. In addition, fracture energy also can be predicted using the Bazant and CEB models. The fracture energy derived from Bazant and CEB models depended on the aggregate size and compressive strength, hence, the result is similar for all notch-to-depth ratios. Therefore, Hillerborg model is more suitable to investigate the effect of the notch-to-depthratio. The range of fracture energy in this study is between $13 \mathrm{~N} / \mathrm{m}$ and $31 \mathrm{~N} / \mathrm{m}$.

Table 2. Summary of fracture energy level at different notch-to-depth ratio of foam concrete.

\begin{tabular}{|c|c|c|c|c|}
\hline \multirow{2}{*}{$\begin{array}{l}\text { Density } \\
\left(\mathrm{kg} / \mathrm{m}^{3}\right)\end{array}$} & \multirow{2}{*}{$\begin{array}{c}\text { Notch-to-depth } \\
\text { ratio }\end{array}$} & \multicolumn{3}{|c|}{ Fracture Energy (N/m) } \\
\hline & & Hillerborg & Bazant & $C E B$ \\
\hline \multirow{3}{*}{1400} & 0.1 & 19.14 & \multirow{3}{*}{16.02} & \multirow{3}{*}{15.10} \\
\hline & 0.3 & 13.52 & & \\
\hline & 0.5 & 6.89 & & \\
\hline \multirow{3}{*}{1600} & 0.1 & 31.50 & \multirow{3}{*}{21.59} & \multirow{3}{*}{25.45} \\
\hline & 0.3 & 25.13 & & \\
\hline & 0.5 & 5.43 & & \\
\hline
\end{tabular}

\subsection{Fracture Energy}

The crack propagation of foam concrete at different notch-to-depth ratios is shown in Table 3 to Table 4 . The crack propagation started at the notch tip and propagated to the loading point. The crack propagated as the flexural tensile cracks increases. 
Table 3. Crack propagation from the tip to the upper surface of foam concrete for $1400 \mathrm{~kg} / \mathrm{m}^{3}$ density.

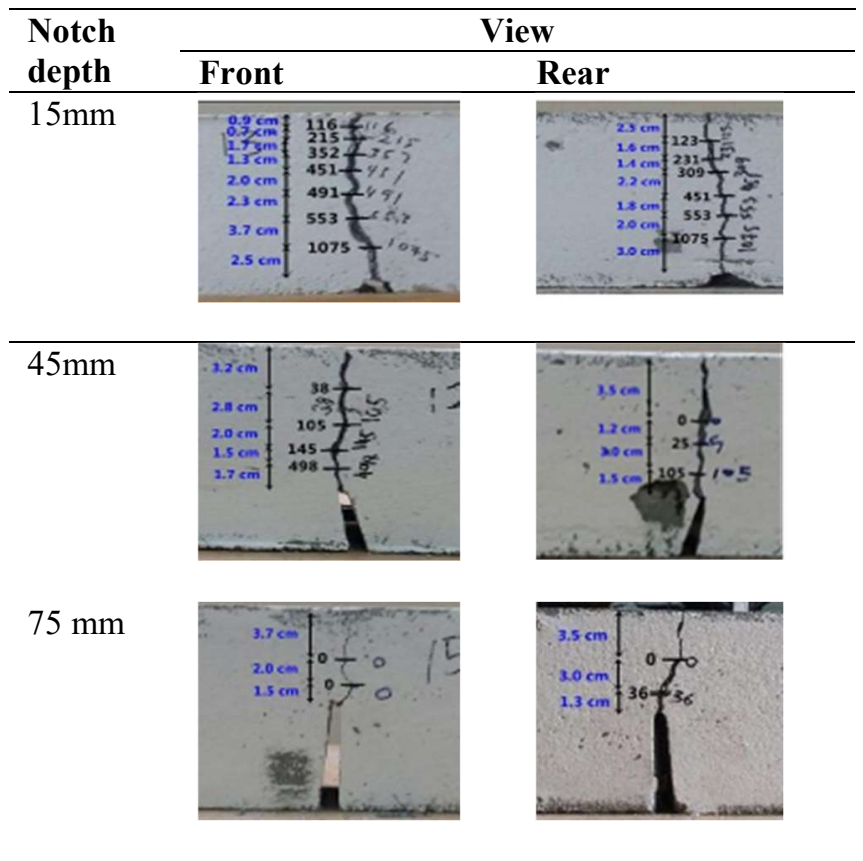

Table 4. Crack propagation from the tip to the upper surface of foam concrete for $1600 \mathrm{~kg} / \mathrm{m}^{3}$ density.

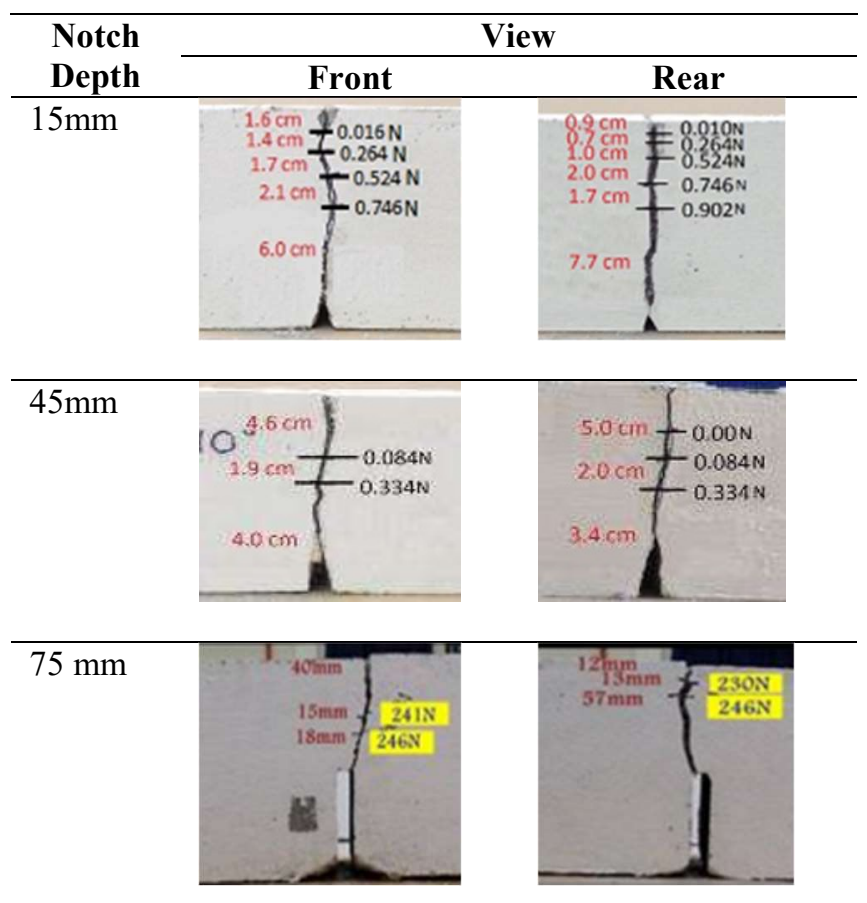




\section{Conclusions}

From the three equation used in determining the level of fracture energy, the study suggested that Hillerborg model is more suitable in investigating the effect of notch-to-depth ratio. From the experimental results, fracture energy decreases as the notch-to-depth ratio increases. This finding is also similar with the effect of notch-to-depth ratio for normal concrete. Thus, fracture energy value of foam concrete is between $13 \mathrm{~N} / \mathrm{m}$ and $31 \mathrm{~N} / \mathrm{m}^{3}$.

The authors would like to thank the Ministry of Higher Education Malaysia and Universiti Tun Hussein Malaysia for funding this research and providing the facilities. This study was conducted under grant scheme FRGS-1219 and GPPS-U573.

\section{References}

1. N.A Rahman, Z.M Jaini, N.A.A. Rahim, S.A.A. Razak, An experimental study on the fracture energy of foamed concrete using v-notched beams, InCIEC, 97-108 (2015)

2. N.A. Rahman, Z.M. Jaini, N.M. Zahir, Fracture energy of Foam Concrete by Means of the Three Point Bending Test on Notched Beam Specimens, ARPN Journal of Engineering and Applied Sciences, 10, 15, 6562 - 6570 (2015)

3. Z.M. Jaini, N, Abd Rahman, R.H.M. Rum and M.M. Haurula, Fracture Energy of Foamed Concrete: Numerical Modelling Using the Combined Finite-Discrete Element Method, Matec Web of Conference, 103 (2017)

4. Marcin Kozłowski, Marta Kadela and Alfred Kukiełk, Fracture energy of foamed concrete based on three-point bending test on nitched beams, Procedia Engineering, 108, 349-354 (2015)

5. A. Hillerborg, The theoretical basis of a method to determine the fracture energy of concrete. Materials and Structure. 18, 4, 291-296 (1985)

6. Z.P. Bazant, Concrete fracture models testing and practice. Engineering Fracture Mechanics, 69, 165- 205 (2002)

7. Comite Euro-International du Beton, CEB-FIB Model Code 1990. Thomas Telford: Lausanne, Switzerland, (1993).

8. RILEM, Fracture mechanics of concrete-test methods, determination of fracture parameters of plain concrete using three-point bend tests. Materials and Structures, 23, 457-460 (1990),p..

9. ASTM E1820-13, Standard test method for measurement of fracture toughness, ASTM International: West Conshohocken, United States, (2014).

10. Naik Partha Uday, Experimental Determination of Fracture Energy by RILEM Method, The International Journal of Engineering and science (IJES), 6 , 3, 106 -115 (2017) 